Consulting Editor

Professor F. H. Sumner, University of Manchester

S. T. Allworth and R. N. Zobel, Introduction to Real-time Software Design, second edition

Ian O. Angell and Gareth Griffith, High-resolution Computer Graphics

Using FORTRAN 77

Ian O. Angell and Gareth Griffith, High-resolution Computer Graphics Using Pascal

M. Azmoodeh, Abstract Data Types and Algorithms

C. Bamford and P. Curran, Data Structures, Files and Databases

Philip Barker, Author Languages for $C A L$

A. N. Barrett and A. L. Mackay, Spatial Structure and the Microcomputer

R. E. Berry, B. A. E. Meekings and M. D. Soren, A Book on C, second edition

G. M. Birtwistle, Discrete Event Modelling on Simula

B. G. Blundell, C. N. Daskalakis, N. A. E. Heyes and T. P. Hopkins,

An Introductory Guide to Silver Lisco and HILO Simulators

T. B. Boffey, Graph Theory in Operations Research

Richard Bornat, Understanding and Writing Compilers

Linda E. M. Brackenbury, Design of VLSI Systems - A Practical Introduction

J. K. Buckle, Software Configuration Management

W. D. Burnham and A. R. Hall, Prolog Programming and Applications

J. C. Cluley, Interfacing to Microprocessors

J. C. Cluley, Introduction to Low Level Programming for Microprocessors

Robert Cole, Computer Communications, second edition

Derek Coleman, A Structured Programming Approach to Data

Andrew J. T. Colin, Fundamentals of Computer Science

Andrew J. T. Colin, Programming and Problem-solving in Algol 68

S. M. Deen, Fundamentals of Data Base Systems

S. M. Deen, Principles and Practice of Database Systems

Tim Denvir, Introduction to Discrete Mathematics for Software Engineering

P. M. Dew and K. R. James, Introduction to Numerical Computation in Pascal

M. R. M. Dunsmuir and G. J. Davies, Programming the UNIX System

D. England et al., A Sun User's Guide

K. C. E. Gee, Introduction to Local Area Computer Networks

J. B. Gosling, Design of Arithmetic Units for Digital Computers

M. G. Hartley, M. Healey and P. G. Depledge, Mini and Microcomputer Systems

Roger Hutty, Z80 Assembly Language Programming for Students

Roland N. Ibbett, The Architecture of High Performance Computers

Patrick Jaulent, The 68000 - Hardware and Software

P. Jaulent, L. Baticle and P. Pillot, 68020-30 Microprocessors and their Coprocessors

J. M. King and J. P. Pardoe, Program Design Using JSP - A Practical Introduction

H. Kopetz, Software Reliability

E. V. Krishnamurthy, Introductory Theory of Computer Science

V. P. Lane, Security of Computer Based Information Systems

Graham Lee, From Hardware to Software - an introduction to computers

A. M. Lister, Fundamentals of Operating Systems, third edition

G. P. McKeown and V. J. Rayward-Smith, Mathematics for Computing

Brian Meek, Fortran, $P L / 1$ and the Algols

A. Mével and T. Guéguen, Smalltalk-80

Barry Morrell and Peter Whittle, $C P / M 80$ Programmer's Guide

Derrick Morris, System Programming Based on the PDP11

Y. Nishinuma and R. Espesser, UNIX - First contact

Pim Oets, MS-DOS and PC-DOS - A Practical Guide

Christian Queinnec, LISP

E. J. Redfern, Introduction to Pascal for Computational Mathematics

Gordon Reece, Microcomputer Modelling by Finite Differences

W. P. Salman, O. Tisserand and B. Toulout, FORTH 
L. E. Scales, Introduction to Non-Linear Optimization Peter S. Sell, Expert Systems - A Practical Introduction

Colin J. Theaker and Graham R. Brookes, A Practical Course on Operating Systems J-M. Trio, 8086-8088 Architecture and Programming

M. J. Usher, Information Theory for Information Technologists

Colin Walls, Programming Dedicated Microprocessors

B. S. Walker, Understanding Microprocessors

Peter J. L. Wallis, Portable Programming

I. R. Wilson and A. M. Addyman, A Practical Introduction to Pascal - with BS6192,, second edition

Non-series

Roy Anderson, Management, Information Systems and Computers

I. O. Angell, Advanced Graphics with the IBM Personal Computer

J. E. Bingham and G. W. P. Davies, A Handbook of Systems Analysis, second edition

J. E. Bingham and G. W. P. Davies, Planning for Data Communications

N. Frude, $A$ Guide to SPSS $/ P C+$ 


\section{Z80 Assembly Language Programming for Students}

\section{Roger Hutty}

School of Mathematics, Computing and Statistics, Leicester Polytechnic

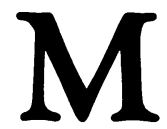

MACMILLAN

EDUCATION 
All rights reserved. No reproduction, copy or transmission of this publication may be made without written permission.

No paragraph of this publication may be reproduced, copied or transmitted save with written permission or in accordance with the provisions of the Copyright Act 1956 (as amended), or under the terms of any licence permitting limited copying issued by the Copyright Licensing Agency, 33-4 Alfred Place, London WC1E 7DP.

Any person who does any unauthorised act in relation to this publication may be liable to criminal prosecution and civil claims for damages.

First published 1981

Reprinted 1982, 1983, 1984, 1985, 1986, 1988

Published by

MACMILLAN EDUCATION LTD

Houndmills, Basingstoke, Hampshire RG21 2XS

and London

Companies and representatives

throughout the world

ISBN 978-0-333-32295-6 ISBN 978-1-349-06155-6 (eBook)

DOI 10.1007/978-1-349-06155-6 


\title{
Contents
}

\author{
Preface
}

Chapter 1 The 280 architecture 1

1.1 Microprocessor systems 1

1.2 The 280 central processing unit 2

1.3 Memory 3

1.4 Instructions 4

1.5 Assembly language 4

Chapter 2 Accumulator and register instructions 6

2.1 Load A register with a value 6

2.2 Add and subtract a value 6

2.3 Add and subtract a register 7

2.4 Load one register with another 7

2.5 Increment and decrement a register 7

2.6 Negate the accumulator 7

2.7 Addressing modes - immediate and extended 8

2.8 Labels 8

2.9 Program 9

Chapter 3 Subroutines and display output 11

3.1 Subroutine concepts 11

3.2 The CALL and RET instructions 12

$\begin{array}{lll}3.3 & \text { Display output } & 13\end{array}$

3.4 Pseudo operations 14

$\begin{array}{ll}3.5 \text { Program } & 15\end{array}$

Chapter 4 Unconditional jumps and keyboard input 16

4.1 Unconditional jumps 16

4.2 Keyboard input 17

4.3 Character codes and values 18

4.4 The EQU pseudo operator 18

$\begin{array}{ll}4.5 \text { Program } & 19\end{array}$

Chapter 5 Flags, conditional jumps and the CP instruction 21

5.1 The flag register 21

5.2 Conditional jump instructions 22

5.3 The compare instruction 23

5.4 Conditional loop termination 24

5.5 Program 24 
Chapter 6 Counting loops and the stack 25

6.1 Counting loops 25

6.2 Number input 27

6.3 The stack 27

6.4 The stack instructions 28

6.5 Saving and restoring registers 29

6.6 Program 30

$\begin{array}{lll}\text { Chapter } 7 & \text { Nested loops and addressing modes } & 31\end{array}$

7.1 Nested loops 31

7.2 Immediate extended and register indirect
addressing modes

7.3 The DEFM pseudo operator 34

7.4 Text output 35

7.5 The subroutine mechanism 35

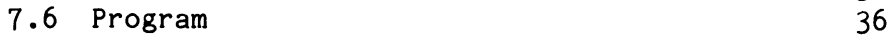

$\begin{array}{lll}\text { Chapter } 8 & \text { Carry and overflow } & 38\end{array}$

8.1 Carry 38

8.2 The carry flag 38

8.3 Overflow 39

8.4 The overflow flag 40

8.5 Conditional CALLs and RETs 40

8.6 Program 41

Chapter 9 Bit operations and the index registers 43

9.1 The BIT test instruction 43

9.2 The SET and RES instructions 44

9.3 The DEFS pseudo operator 44

9.4 The index registers 44

9.5 Expressions 45

9.6 Jump tables 46

9.7 Program 48

Chapter 10 Shift instructions, multiply and divide 49

10.1 The SRL instruction 49

10.2 The SRA instruction 50

10.3 The SLA instruction $\quad 50$

10.4 8-bit multiplication and division 51

10.5 Program 52

Chapter 11 Logical operations and macros 54

11.1 Logic operators 54

11.2 Logical instructions $\quad 54$

11.3 Masking $\quad 55$

11.4 Macros $\quad 55$

11.5 Conditional pseudo operations 58

$\begin{array}{ll}11.6 \text { Program } & 59\end{array}$ 
12.1 Accumulator rotate instructions 61

12.2 Register and byte rotate instructions 63

12.3 Packing and unpacking 63

12.4 Parity 64

12.5 The parity flag 65

$\begin{array}{ll}12.6 \text { Program } & 66\end{array}$

Chapter 13 16-bit and multiple byte arithmetic 67

13.1 The DEFW pseudo operator 67

13.2 The 16-bit ADD, $A D C$ and SBC instructions 68

13.3 Extended loops $\quad 70$

13.4 Multiple byte arithmetic 72

$\begin{array}{ll}13.5 \text { Program } & 73\end{array}$

Chapter 14 Block transfer and search instructions 74

14.1 Block transfer instructions $\quad 74$

14.2 Block search instructions $\quad 77$

$\begin{array}{ll}14.3 \text { Program } & 79\end{array}$

$\begin{array}{lll}\text { Chapter } 15 \text { Decimal arithmetic } & 80\end{array}$

$15.1 \mathrm{BCD}$ representation 80

15.2 BCD arithmetic 81

15.3 The DAA instruction 82

15.4 The digit rotate instructions 83

$\begin{array}{ll}15.5 \text { Program } & 85\end{array}$

$\begin{array}{lll}\text { Chapter } 16 & \text { Miscellaneous instructions } & 87\end{array}$

16.1 The NOP instruction $\quad 87$

$\begin{array}{ll}16.2 \text { The auxiliary registers } & 87\end{array}$

16.3 Input and output instructions 88

16.4 Interrupt instructions 88

Appendix A Binary and hexadecimal number systems 89

A.1 Binary and hexadecimal numbers 89

A.2 Binary and hexadecimal arithmetic 90

A.3 Decimal to hexadecimal conversion 91

A.4 Hexadecimal to decimal conversion 91

A.5 Binary-hexadecimal conversion 92

A.6 Decimal-binary conversions 92

A. 7 Bytes 93

A.8 Signed (2's complement) numbers 93

Appendix B Hexadecimal-decimal conversion tables 96 
Appendix C Summary of Z80 instructions 98

Table C.1 Summary of flag operations 99

Table C.2 8-bit load group 100

Table C.3 16-bit load group 101

Table C.4 Exchange group and block transfer 102 and search group

Table C.5 8-bit arithmetic and logical group 103

Table C.6 General purpose arithmetic and CPU control groups 104

Table C.7 16-bit arithmetic group $\quad 105$

Table C.8 Rotate and shift group 106

Table C.9 Bit set, reset and test group 107

Table C.10 Jump group 108

Table C.11 Call and return group 109

Table C.12 Input and output group 110

Appendix D Display and keyboard character codes 111

Appendix E Expression operators 112

$\begin{array}{ll}\text { Exercise answers } & 113\end{array}$

$\begin{array}{ll}\text { Index } & 126\end{array}$ 


\section{Preface}

This learning text, based on the $Z 80$ Assembly Language, enables a student to develop through suitable exercises and programming practice a professional approach to programming and produce a work of quality. There is an art to programming: it is not enough for a student to know the rules of a language, it is equally important to develop a readable and intelligible program which has style and uses the best techniques.

This book is not an ordinary text book - it is a learning text. It is intended to accompany a course of lectures or be used as the text for a tutor-assisted, self-instructional course. However, it is suitable as a teach-yourself text for students who have an appreciation of computer programming, or who already know a little of the $Z 80$ assembly language. Practising $Z 80$ assembly language programmers may find the text useful for reference purposes.

The text is divided into sixteen chapters. Each chapter can be used as a self-contained unit for teaching purposes to be used for one or two weeks' lectures and tutorial, or as selfinstructional unit. Each chapter assumes that a student has satisfactorily completed the previous chapters.

A chapter consists of short narratives; each narrative covers one or two concepts and is followed by an exercise. The narratives move fast, the exercises are challenging and they encourage students to make many discoveries for themselves, thereby allowing the rapid development of skills. Every opportunity is taken to expose practical problems and develop good programming habits right from the start.

The narratives, the exercises, the exercise answers and the program at the end of each chapter all play an equally important part in the learning process. The exercises have been chosen to be a real test of a student's understanding of both concept and detail and to extend, sometimes by discovery, the knowledge and understanding gained in the narrative. Some of the exercise answers include notes on the answers which also extend a student's knowledge and understanding. A program is specified at the end of each chapter to be coded, run and tested on a computer 
system. Each program is designed, as far as is possible, to include the concepts contained in the chapter.

The exercises should be done when they are encountered and before continuing with the text. Additionally, the programs should at least be coded before continuing with the next chapter. Many students will be able to work through the text without assistance, allowing a tutor to concentrate his attention on those students who are unable to complete the text on their own.

The whole text is designed on the premise that one sure way to learn a programming language is by plenty of practical experience - just like learning a foreign language. Proficiency in programming is acquired by writing it. That is one reason why practical exercises have been inserted throughout the text and a program is included at the end of each chapter. The text contains many exercises which call for written answers; it is essential that the answers are written down. Eager students are sometimes tempted to answer the questions mentally in their impatience to make pogress with the subject - they should resist this temptation!

Throughout the book, modular design of assembly language programs is encouraged. To allow this, subroutines are introduced early on in the course in Chapter 3.

The text is also designed so that students can code and run programs at the earliest possible stage in a course.

At the end of each chapter there is a program specification. The program should be coded, run and tested, preferably before passing on to the next chapter, although this may not be practicable; however, the program should at least be coded before looking at the next chapter. The program should be a fully correct working version which adheres exactly to the specification. A program is no use to anyone if it does not do exactly what is required of it.

Only one program is specified at the end of each chapter so that a student can concentrate his effort on that one program.

The programs have been carefully chosen to be stimulating and have a visual reward for success - all programs produce some form of output on a display.

If necessary, the programs can be replaced by other programs for specialist courses, although the programs in the text have been carefully chosen to cover as many aspects of $Z 80$ assembly programming as possible.

Instead of covering all of a topic at once, most topics are spread over a few chapters and each chapter covers parts of a few topics. This allows more relevant programs to be written earlier in a course and it makes the text more interesting thereby helping a student's concentration. Additionally, because a topic 
is spread throughout the text, a student has time gradually to assimilate the concepts contained within a topic and to absorb each concept before proceeding to the next.

One problem encountered by tutors teaching programming languages to a group of students is the wide variation in the students' rates of learning the language - even groups of students with the same background. Consequently, a favoured method of teaching programming languages is by tutor-assisted, self-instructional methods, so that students may learn at their own rate and not become bored or lost. This text is particularly suitable for such a course.

This book is not written for use with one particular $Z 80$ computer system - it can be used with any 280-based microcomputer. A minimum configuration of a $Z 80$ processor, screen and keyboard is assumed to be available for the practical programs.

This book is suitable for BSc, HND and BEC/TEC courses in computing and engineering and as a reference book for practising Z80 Assembly Language programmers.

\section{ACKNOWLEDGEMENTS}

My thanks to Leicester Polytechnic for allowing me to use their computer facilities for the development of programs and production of the book, and to Bob Reeve, of Wolverhampton Polytechnic, for his thorough checking of the text and many suggested improvements. Also, I wish to thank my wife, Susan, for her support in many ways, particularly in the typing of the text using a word processor. Thanks too to Nicolas and Elisabeth for their patience on occasions when having to wait for parental care and attention.

Roger Hutty 